\title{
Informed consent for uninsured services: a primary care perspective on the new childhood vaccines
}

\author{
J. Michael Paterson, leva M. Neimanis, Cindy R. Goebel, Daniel J. Kraftcheck
}

U niversal childhood vaccination programs have been key to reductions in child morbidity and mortality caused by common infectious diseases over the past half century. In Ontario, other than the hepatitis B vaccine (which is funded and administered through schoolbased programs), routine childhood vaccinations such as those against polio, tetanus and diphtheria are required for public school admission, are paid for by the province and are administered largely by family doctors. As new vaccines have been developed and proven safe and effective against other common infectious agents, such as Haemophilus influenzae type b, they have typically been added to the vaccination schedule with full funding. However, this practice stopped in May 1999, when the National Advisory Committee on Immunization (NACI) recommended routine vaccination of young children against varicella. ${ }^{1}$ Since then, there have also been calls for routine use of the meningococcal vaccine ${ }^{2}$ and the pneumococcal conjugate vaccine. ${ }^{3}$ Facing costs of up to $\$ 800$ per child for universal coverage of these 3 vaccines, on top of existing vaccine expenditures of over $\$ 67$ million per annum, ${ }^{4}$ the province's initial reaction was to offer targeted funding (of $\$ 5.6$ million) to protect specific high-risk children. ${ }^{5}$ The campaign platform of the newly elected Liberal government gave hope of further support for the varicella and meningococcal vaccines. ${ }^{6} \mathrm{With}$ encouragement from public health officials, ${ }^{7-9}$ politicians ${ }^{10}$ and parents, ${ }^{11}$ further though incomplete funding was recently announced. ${ }^{12,13}$

In February 2003 the federal government allocated \$45 million over 5 years to "assist in the pursuit of a national immunization strategy," ${ }^{14}$ and the latest federal budget promised a further $\$ 300$ million over 3 years "to support the introduction of new and recommended childhood and adolescent vaccines (as proposed by the NACI)." ${ }^{15}$ These are important steps forward. But until such time as governments can agree on national standards for coverage, the potential for "patchwork policy" will continue to exist. ${ }^{16,17}$ In the interim, what are parents and practitioners to do? Should family doctors recommend "uninsured" vaccines? What should be said about them? And what, if anything, should be done if parents refuse vaccination? In this commentary we share results from a recent survey of Hamiltonarea practice patterns, our response to the findings and some thoughts on how a national approach to informed consent for childhood vaccines could help jump-start the national immunization strategy.

\section{Current standards of care for the new childhood vaccines}

The Canadian Medical Protective Association (CMPA) recently clarified that "Whether physicians should notify parents of a new vaccine depends on whether administration of the vaccine is considered the 'standard of care' by other physicians in the community." 18 Typically, legal judgements about what constitutes a standard of care are established by courts on a case-by-case basis through the testimony of expert witnesses, although published clinical practice guidelines and the recommendation of expert panels, such as the NACI, can be instructive. ${ }^{19-21}$ Accordingly, the CMPA concluded that "It seems likely that a court would hold that recommending the pneumococcal, meningococcal, and varicella vaccines has become part of the standard of care for [Canadian] physicians." ${ }^{\prime 18}$ It also advised that related discussions about informed consent should include 4 key elements: disclosing material risks, benefits and financial costs of vaccination, as well as the possible consequences of refusal; providing written material on these topics; answering parents' questions; and clearly documenting the outcome of the discussion. Finally, the CMPA suggested that physicians may wish to have parents who decline vaccines sign a "consent form," confirming that they have been fully informed of the risks and benefits of the vaccine and the consequences of refusal. ${ }^{18}$

We understood the CMPA's position. However, given evidence of limited uptake of the varicella vaccine ${ }^{22-24}$ and lack of comparable data for the others, we questioned whether routinely offering the new vaccines had become prevalent practice in typical primary care settings. To help us answer this question, we surveyed members of our hospital's family medicine department who were in full-time office practice. Sixty-six (80\%) of the 82 physicians responded; the participants were more frequently female, certificants of the College of Family Physicians of Canada and practising in non-fee-for-service settings than respondents to other surveys of the area's family doctors (all $p<$ $0.05){ }^{25,26}$ Thus, our results cannot be generalized, and they probably overstate even local prescribing and documentation practices; nonetheless, given the limited data on these issues, several findings bear mention.

Despite limited public funding for the new vaccines, self-reported behaviours were generally consistent with the 
CMPA's advice on 2 fronts: most physicians reported routinely recommending the vaccines $(60 \%$ to $70 \%$, depending on the vaccine), and most reported providing parents with both verbal and written information and documenting the outcome of their discussions (about $70 \%$ and $80 \%$, respectively). These findings support the notion that offering and seeking consent to administer the new vaccines had become a local "standard of care." On the other hand, none of our respondents reported asking parents to sign an "informed refusal" form when vaccines were declined.

\section{Liability and consent for new vaccines}

The survey answered some of our questions, but raised others. Thirty to forty percent of respondents admitted to not routinely offering the new vaccines (likely an underestimate of the true prevalence), and cost was a frequent and consistently reported barrier to recommendation. These findings underline the difficulty that physicians (who know their patients' social and financial circumstances) face in advocating treatments that they know are unaffordable. Parallels can be drawn with other situations in which access to "recommended" interventions is limited by various forms of rationing, such as waiting lists for insured services (e.g., major joint replacement, multidisciplinary diabetes care, screening colonoscopy for high-risk patients) or ability to pay for services that are uninsured (e.g., the prostate-specific antigen test).

As an interim measure, we developed a standard vaccine information sheet, distributed it to colleagues and recommended that they give it to parents routinely (see Box 1 for examples of published vaccine information sheets, as well as other vaccination-related resources). The one-page information sheet presented basic information regarding the risks and benefits of the uninsured vaccines, who should get them, how they are administered and what they cost. If similar provincial or, better, national vaccine information sheets were to be developed, their distribution could be legislated. Under the US National Childhood Vaccine Injury Act, for example, parents must receive a vaccine information statement produced by the Centers for Disease Control and Prevention before administration of each vaccine dose. ${ }^{27,28}$ Currently, this Act applies only to publicly funded vaccines, but we see little reason why the concept could not be extended to all "recommended" vaccines. In fact, development and dissemination of Canadian vaccine information sheets, perhaps in the form of a booklet distributed to parents on discharge from hospital after the birth of a child, could be a small but important early contribution of the fledgling national immunization strategy.

Whether Canadian physicians are prepared to have parents sign forms when they decline vaccines is a separate issue. On this question, our colleagues' practice was not in line with the CMPA's advice. ${ }^{18}$ However, we believe it is consistent with other situations in which highly effective preventive interventions are thoroughly explained and rec- ommended to patients but declined; in these situations, brief, proper documentation has always sufficed. Evidence exists that written contracts can help some patients accept and adhere to preventive interventions. However, to our knowledge, use of such contracts is not widespread, and their application to vaccines is relatively new. The Ameri-

\section{Box 1: Web sites presenting vaccination information for physicians and parents}

\section{Health Canada, Division of Immunization and Respiratory Disease}

www.hc-sc.gc.ca/pphb-dgspsp/dird-dimr /immunization_e.html

Includes links to the Canadian Immunization Guide (2002 edition), the Canadian vaccination schedule and other resources about vaccination practices in Canada

\section{Canadian Coalition for Immunization Awareness and} Promotion

www.immunize.cpha.ca

Provides a variety of resources to inform parents and health care providers about vaccination, including a comprehensive set of links to articles and links about specific vaccine-preventable diseases

\section{Canadian Paediatric Society}

www.caringforkids.cps.ca/immunization/index.htm Includes vaccination information sheets for 9 childhood vaccines, as well as links to other vaccination resources

\section{US Centers for Disease Control and Prevention}

www.cdc.gov/nip/publications/vis/

Includes vaccine information statements for 16 childhood vaccines, as well as information on combination vaccines; translated versions (in more than 20 languages) also available through this site

\section{UK National Health Service}

www.immunisation.org.uk

Includes vaccine information sheets for 9 childhood vaccines, as well as other information about vaccination practices in the United Kingdom

\section{Immunise Australia Program}

immunise.health.gov.au

Provides information on various Australian immunization programs, including resources about specific vaccine-preventable diseases, such as fact sheets for parents (available in English and several other languages)

\section{World Health Organization}

www.who.int/immunization_safety/en/

Provides detailed information, including training and communication materials, about the WHO's effort to improve immunization safety 
can Academy of Pediatrics recently published a template "informed refusal" document, with the aims of protecting its members and making parents think twice about the consequences of nonvaccination. ${ }^{29}$ Legislation with similar goals exists in British Columbia for parents who decline antibiotic prophylaxis for ophthalmia neonatorum, ${ }^{30}$ and some $\mathrm{BC}$ nurses were recently asked to sign informed refusal forms for influenza immunization. ${ }^{31}$ So precedents for such forms do exist in Canada. However, whether individual physicians perceive themselves to be at sufficient legal risk to warrant using such forms is an open question. Our preliminary data suggest they may not. Perhaps a more important question is "Is this the approach to patient counselling and care we wish to take?"

From the Departments of Family Medicine, St. Joseph's Healthcare Hamilton and McMaster University, Hamilton, Ont. (Paterson, Neimanis, Goebel, Kraftcheck); and the Institute for Clinical Evaluative Sciences, Toronto, Ont. (Paterson)

\section{Competing interests: None declared.}

Contributors: Ieva Neimanis conceptualized the study. Michael Paterson collected and analyzed the data and drafted the article. All authors contributed to developing the questionnaire, interpreting data and revising the article for important intellectual content; and all approved the final draft for publication.

Acknowledgements: We are grateful to our colleagues who participated in this survey and to Carol Conroy for her help with data entry.

\section{References}

1. National Advisory Committee on Immunization. Statement on recommended use of varicella virus vaccine. Can Commun Dis Rep 1999;25(ACS-1):1-16.

2. National Advisory Committee on Immunization. Statement on recommended use of meningococcal vaccines. Can Commun Dis Rep 2001;27(ACS-6):2-36.

3. National Advisory Committee on Immunization. Statement on recommended use of pneumococcal conjugate vaccine. Can Commun Dis Rep 2002;28(ACS2): $1-32$.

4. Office of the Provincial Auditor of Ontario. 2003 annual report. Toronto: The Office; 2003. Available: www.auditor.on.ca/english/reports/en03/en03 fm.htm (accessed 2004 Jun 30).

5. Eves government introduces two vaccines to further protect children against disease [news release]. Toronto: Ministry of Health and Long-Term Care; 2003 Apr 28. Available: ogov.newswire.ca/ontario/GPOE/2003/04/28/c5281 .html?lmatch=\&lang=_e.html (accessed 2004 Jun 30).

6. Ontario Liberal Party 2003 election platform [online]. Toronto: Ontario Liberal Party; 2003 Mar. Available: www.ontarioliberal.com/en/platform (accessed 2004 Mar 24).

7. Endorsement of the National Immunization Strategy. Newmarket (ON): Regional Municipality of York, Health and Emergency Medical Services Committee; 2004 Feb 5. Available: www.region.york.on.ca/NR/rdonlyres/sa7pvcifez 7rh7tgdsrxzavzsscrt2yy4mvwftmrvwn7mi4czzc7j4lxalrm2pezqf5ixp7akrbdnrmftwt $4 \mathrm{cmt} 63 \mathrm{~g} / \mathrm{Feb}+5+$ Endorsement.pdf (accessed 2004 Sep 6).

8. Minutes of meeting of Region of Waterloo Community Services Committee, held 2003 Nov 18. Kitchener (ON): Region of Waterloo; 2003. Available: www.region.waterloo.on.ca/web/Region.nsf/0/09ee60b90ad6633185256de40 06928c1? OpenDocument (accessed 2004 Jul 02)

9. Seasons D. Report PH-03-074: provincial funding for new vaccines. Kitchener (ON): Region of Waterloo, Public Health Branch; 2003 Nov 18.

10. Bill 57, An Act to Amend the Health Insurance Act to Make Various Immu- nizations Insured Services, 1st sess., 38th Leg., Ontario, 2004 (2nd reading, April 29, 2004). Available: www.ontla.on.ca/library/bills/381/57381.htm (accessed 2004 Jul 2).

11. CTV.ca News Staff. Best shot [on-line]. Toronto: CTV.ca; 2004 Feb 6 Available:www.ctv.ca/servlet/ArticleNews/story/CTVNews/1076086445321 71495645///?hub=WFive (accessed 2004 Jul 2).

12. Ferguson R. Free vaccine program for kids unveiled. Toronto Star 2004 Jun 10. Available: www.thestar.com (accessed 2004 Jun 10).

13. Canadian Press. Ontario rolls out phase 2 of free vaccinations. Toronto Star 2004 Aug 31. Available: www.thestar.com/NASApp/cs/ContentServer?pagename $=$ thestar $/$ Layout $/$ Article_Type1\&call_pageid=971358637177\&c=Article $\&$ cid $=10$ 93948627361 (accessed 2004 Aug 31).

14. The budget plan 2003. Ottawa: Department of Finance Canada; 2003. Available: www.fin.gc.ca/budget03/pdf/bp2003e.pdf (accessed 2004 Sep 6).

15. Budget plan 2004. Ottawa: Department of Finance Canada; 2004. Available: www.fin.gc.ca/budget04/bp/bptoce.htm (accessed 2004 Jul 2).

16. A patchwork policy: vaccination in Canada [editorial]. CMA7 2003;168(5):533.

17. Anis AH, Guh D, Wang X. A dog's breakfast: prescription drug coverage varies widely across Canada. Med Care 2001;39:315-26.

18. Sirnick A, Ross M. New childhood vaccines. Ottawa: Canadian Medical Protective Association; [date unknown]. Available: www.cmpa-acpm.ca/portal /pub_index.cfm?LANG=E\&URL=cmpa\% 5Fdocs\% 5Cenglish $\% 5$ Cresource \% 5Ffiles\%5Cinfoletters\%5Ccommon\%5C2002\%5C12\%5Cmpl\%5Finfo\%5Fletter \%5F2002\%5F12b\%2De\%2Ehtml (accessed 2004 Sep 6).

19. Caulfield T, Siminoski K. Physicians' liability and drug formulary restrictions. CMA7 2002;166(4):458-60.

20. Hartz A, Lucas J, Cramm T, Green M, Bentler S, Ely J, et al. Physician surveys to assess customary care in medical malpractice cases. 7 Gen Intern Med 2002; 17:546-55.

21. Hall MA, Green MD. Empirical approaches to proving standard of care in medical malpractice cases. Wake For Law Rev 2002;37:663-74.

22. Persaude D, Teape-Humphrey L, Adelstein R, Domb S, Jaakkimainen L. Peril of the pox. Are primary care providers aware of varicella vaccination guidelines? Can Fam Physician 2002;48:316-23.

23. DeSerres G, Duval B, Boulianne N. Impact of vaccine cost and information about complications of varicella on parental decisions regarding varicella vaccine. Can 7 Public Health 2002;93:114-6.

24. de Courval FP, De Serres G, Duval B. Varicella vaccine. Factors influencing uptake. Can 7 Public Health 2003;94:268-71.

25. Profile of family physicians / general practitioners (FPs) in Ontario. Results of the 2001 National Family Physician Workforce Survey. Toronto: College of Family Physicians of Canada; 2002 Dec. Available: www.cfpc.ca/local/files/Programs/Janus\% 20project/NFPWS\%20Regional\%20Report-\%20ON.pdf (accessed 2004 Jul 2).

26. The CFPC National Family Physician Survey - regional report (Ontario with the exception of postal codes $L \& M$ ) [1997/1998]. Toronto: College of Family Physicians of Canada; 1998, updated 2003 Jan 5. Available: www.cfpc.ca/english /cfpc/research/janus\%20 project/nfps/regional/ontario/default.asp?s=1 (accessed 2004 Jul 2).

27. Instructions for the use of vaccine information statements. Atlanta: Centers for Disease Control and Prevention; 2003. Available: www.cdc.gov/nip/publications/VIS/vis-instructions.pdf (accessed 2004 Jul 2).

28. Vaccine information statements. Atlanta: Centers for Disease Control and Prevention; 2004. Available: www.cdc.gov/nip/publications/VIS/default.htm (accessed 2004 Jul 2).

29. Documenting parental refusal to accept vaccination. Elk Grove Village (IL) American Academy of Pediatrics; [date unknown]. Available: www.cispimmunize .org/pro/pdf/RefusaltoVaccinate_2pageform.pdf (accessed 2004 Jul 2).

30. Health Act Communicable Disease Regulation, B.C. Reg. 4/83, s. 17. Available: www.qp.gov.bc.ca/statreg/reg/h/health/4_83.htm (accessed 2004 Jul 2).

31. Bulletin: Don't sign "informed refusal" forms for influenza immunization. Burnaby (BC): British Columbia Nurses Union; 2003 Oct 14. Available: www.bcnu.org/Bulletins_2003/bull_064_2003.htm (accessed 2004 Jul 2).

Correspondence to: Michael Paterson, Institute for Clinical Evaluative Sciences, G106-2075 Bayview Ave., Toronto ON M4N 3M5; fax 416 480-6048; paterson@ices.on.ca 